\title{
Prevalence of cystathionine beta synthase gene mutation 852Ins68 as a possible risk for neural tube defects in eastern India
}

\author{
A.K. Saxena ${ }^{1}$, J. Gupta ${ }^{1}$, S. Pandey ${ }^{2}$, A.N. Gangopadhaya ${ }^{3}$ and \\ L.K. Pandey ${ }^{2}$ \\ ${ }^{1}$ Center of Experimental Medicine and Surgery, Institute of Medical Sciences, \\ Banaras Hindu University, Varanasi, India \\ ${ }^{2}$ Department of Obstetrics and Gynecology, Institute of Medical Sciences, \\ Banaras Hindu University, Varanasi, India \\ ${ }^{3}$ Department of Pediatric Surgery, Institute of Medical Sciences, \\ Banaras Hindu University, Varanasi, India \\ Corresponding author: A.K. Saxena \\ E-mail: draksaxena1@rediffmail.com
}

Genet. Mol. Res. 10 (4): 2424-2429 (2011)

Received January 18, 2011

Accepted May 16, 2011

Published October 7, 2011

DOI http://dx.doi.org/10.4238/2011.October.7.4

\begin{abstract}
Cystathionine beta synthase gene (C $\beta S)$ catalyzes the condensation of homocysteine with serine, forming cystathionine by the transsulfuration pathway. Disruption of C $\beta S$ enzyme activity due to defective folic acid metabolism increases the risk factor for neural tube defects. We evaluated the C $\beta S$ gene mutation in 25 children with neural tube defects (NTDs), including lumbosacral and thoracic myelomeningocele and open NTDs and mothers of cases, along with 25 healthy children and their mothers, serving as controls. Genomic DNA was isolated to assess the polymorphism of 852Ins68 in the C $\beta S$ gene using PCR-RFLP analysis and nucleotide sequencing techniques. The 68-bp insertion was observed in one of the 25 NTD cases (lumbosacral myelomeningocele), and in two of the mothers of NTD cases. Statistical analysis was carried out using the Fischer exact
\end{abstract}


probability test, which showed a lack of significance $(\mathrm{P}>0.05)$, but the odds ratio of 2.08 with $95 \%$ confidence interval of 0.17-24.6 in NTDs mother was quite high because of the small sample size. However, the study was further extended to find out the involvement of specific nucleotide sequences, which again confirmed the 852Ins68 insertion and replacement of nucleotides (TCCAT to GGGG) in lumbosacral myelomeningocele (due to other category of NTDs), suggesting that it could be an independent risk factor for birth defects, including NTDs.

Key words: Cystathionine beta synthase; 852Ins68; Neural tube defects

\section{INTRODUCTION}

Neural tube defects (NTDs) are known to be the most common defect of a group of congenital malformations of the central nervous system after cardiovascular anomalies, which cause fetal loss and disabilities in surviving infants. In humans, NTDs include anencephaly, myelomeningocele and open NTD (Thomas et al., 1994; Mosley et al., 2009). The known possible mechanisms for NTDs are defective folic acid metabolism, genetic susceptibility and environmental factors (Botto et al., 1999). Epidemiological studies indicate that NTDs occur in approximately one in 1000 live births in the United States population, but the highest incidence of NTDs is recorded in northern China and certain parts of England (Moore et al., 1997). The cystathionine beta synthase (C $\beta S)$ gene is located at chromosome $21 \mathrm{q} 22.3$ position and involves a large number of mutations including missense and nonsense mutations such as insertion, deletion and splice variants (amino acid substitution) (Munke et al., 1988; Tsai et al., 1996b; Kraus et al., 1998). Cystathionine beta synthase is a key enzyme (E.C. 4.2.1.22) of methionine metabolism catalyzing the condensation of homocysteine with serine to remove homocysteine from the methionine cycle and to commit it to the transsulfuration pathway. The mutation of the C $\beta S$ gene disrupts enzyme activity, which leads to hyper-homocysteinemia, and the accumulation of homocysteine causes several disorders including vasculotoxic, cardiovascular disorder, osteoporosis, and neurotoxicity resulting in cognitive dysfunction, mental retardation and NTDs (Mudd et al., 2001).

The exact etiopathology of NTDs has not been clearly defined in the literature, but studies have shown that women with folic acid deficiency are more prone to having a child with NTDs, although three mutations of the CBS gene, namely T833C transition, G919A and the 844ins68 insertion sequence, are the most frequent in exon 8 (Tsai et al., 1996a,b; Sperandeo et al., 1996). The present study was designed with the aim to examine the prevalence of genetic polymorphism of the C $\beta S$ gene in NTD cases and also to determine the risk factor when compared with controls of the same age and ethnic groups for statistical analysis.

\section{MATERIAL AND METHODS}

\section{Subjects}

We studied 25 children aged between 5 days and 5 years (males and females) with 
NTD, 25 mothers of NTD aged 20 to 30 years from the Department of Pediatric Surgery, Obstetrics and Gynecology of S.S Hospital, Institute of Medical Sciences, B.H.U. Varanasi, India. The control group consisted of 25 unrelated children of the same age groups and their mothers (25) from the same province to avoid ethnic variation. Institutional ethical approval was obtained and written informed consent was given by the participants' relatives or their guardians before collection of blood samples. The patients who were under treatment of any kind were excluded from the present study, and only those patients with clinically diagnosed NTDs were included.

\section{Genetic analysis}

Genomic DNA was isolated from peripheral blood samples using a standard protocol (Miller etal., 1988) and quantified by spectrophotometry. Analysis of the C $\beta$ S gene mutation was carried out by PCR amplification using specific forward (5'-GTTGTTAACGGCGGTATTGC$3^{\prime}$ ) and reverse (5'-GTTGTCTGCTCCGTCTGGTT-3') primers in a total volume of $50 \mu \mathrm{L}$ containing 50-100 ng genomic DNA, 20 pmol of each primer, $200 \mu \mathrm{M}$ of each dNTP with Taq buffer (10 mM Tris- $\mathrm{HCl}, \mathrm{pH} 8.3,50 \mathrm{mM} \mathrm{KCl}), 3.0 \mathrm{mM} \mathrm{MgCl}_{2}$ and $3 \mathrm{U}$ Taq polymerase (New England Biolabs). The amplified product of PCR $(6 \mu \mathrm{L})$ was digested using the specific restriction enzyme $\mathrm{Hae} \mathrm{III}$ at $37^{\circ} \mathrm{C}$ for $3 \mathrm{~h}$ in a reaction volume of $25 \mu \mathrm{L}$ containing $1 \mathrm{U}$ HaeIII (New England Biolabs) and NEB buffer $(2.5 \mu \mathrm{L})$. The restriction fragments were separated on a $3 \%$ agarose gel stained with ethidium bromide and visualized with Gel Doc System (SR Biosystem) for further characterization.

\section{Sequencing analysis}

The amplified PCR products were purified from the agarose gel and sequenced in both the forward and reverse direction by the Sanger DNA sequencing method.

\section{Statistical analysis}

Thre Fisher exact probability test was used to find out the frequency of genotype distribution of the C $\beta S$ gene polymorphism between NTD cases, case mothers, controls, and control mothers.

\section{RESULTS}

We selected the known primers of the C $\beta S$ gene from the sequence of exon 8 as noted in the preceding section and expected a 171-bp DNA fragment amplified by PCR, visualized on an agarose gel containing ethidium bromide (Figure 1). We observed an extra band of $239 \mathrm{bp}$, which includes the insertion fragment of $68 \mathrm{bp}$ in addition to the amplified PCR product. After confirming the C $\beta S$ gene mutation, the data were further evaluated by DNA sequencing of the PCR product to determine any novel mutation. Interestingly, the mutation was confirmed at position 852, i.e., replacement (TCCAT to GGGG) of nucleotides, which created a new recognition site (GGCC) for the restriction enzyme HaeIII as shown in Figure 2. 


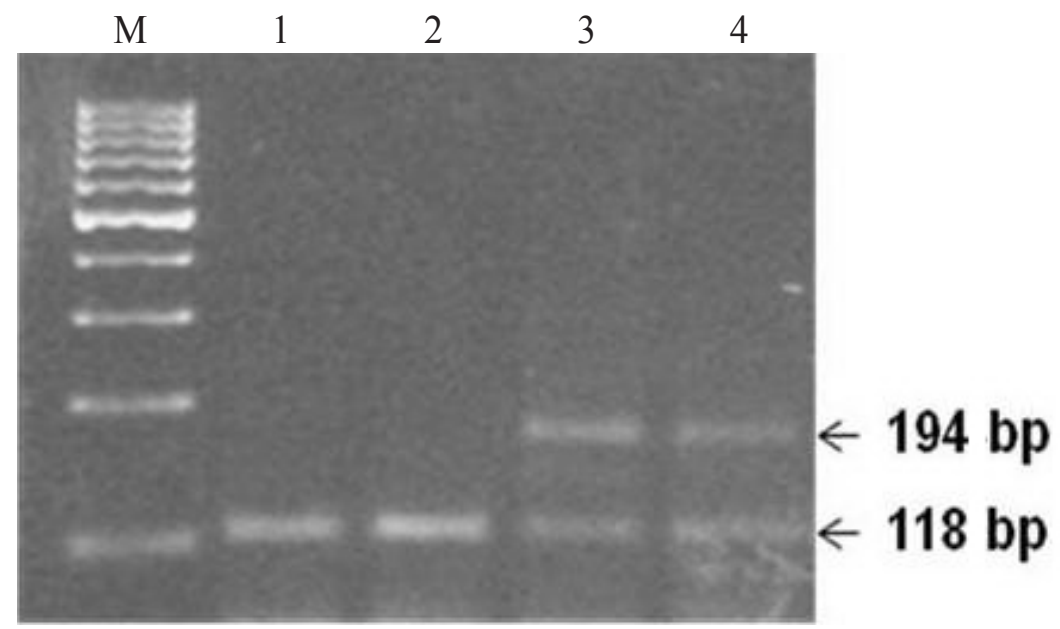

Figure 1. PCR-based RFLP analysis of the C $\beta$ S 852Ins68 gene after digestion with HaeIII restriction enzyme. Lane $M=$ DNA molecular weight markers (100-bp ladder). Lanes 1 and $2=$ RFLP digested product of the C $\beta S$ gene in normal control showed only one band of $118 \mathrm{bp}$. Lanes 3 and $4=$ fragments of 194 and $118 \mathrm{bp}$ after cleavage of a 239-bp inserted PCR product in neural tube defect case and case mother, respectively, on $2 \%$ agarose gel.

A

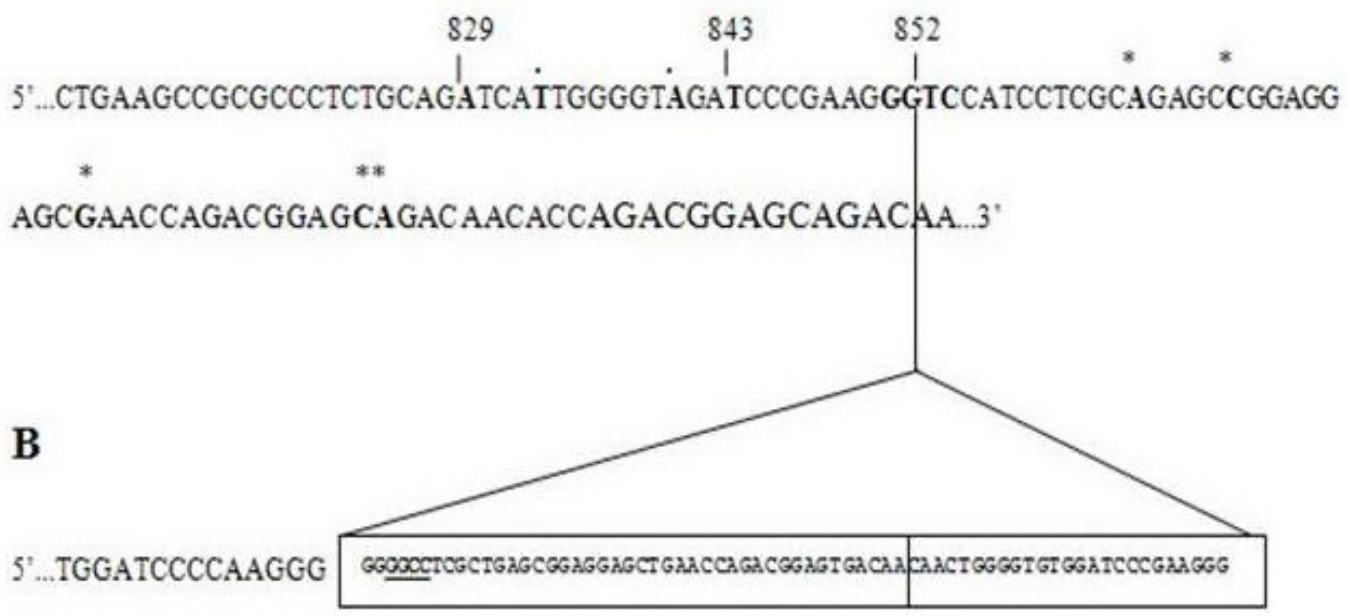

CATCCTCGCAGAGCCGGAGGAGCGAACCAGACGGAGCAGACAACACC ...3'

Figure 2. Characterization of the C $\beta S$ gene mutation. Comparison of sequence of exon 8 of a normal allele (A) and individual with a 68-bp insertion (B). The sequence of the first 45 nucleotides of the insertion is identical to that of 42 nucleotides after the site of insertion at nucleotide 852 towards the $3^{\prime}$ end of exon 8 with some exception as indicated by asterisks. The sequence of the remaining 23 nucleotides is identical to the wild-type sequence of the first 21 nucleotides (831-852) from the $5^{\prime}$ end of the exon in the normal allele with some differences as indicated by dots. In the insertion of $68 \mathrm{bp}$ at nucleotide 852 , five bases are replaced by tetra-guanine bases (TCCAT $\rightarrow$ GGGG), which created a recognition sequence for the restriction enzyme HaeIII (GGCC) as represented by underline in the box in B. 
The genotype frequency of the C $\beta S$ gene (insertion) mutation in the heterozygous state appears to be more prevalent in the mothers of NTD cases $(8 \%)$ when compared with control mothers $(4 \%)$. The odds ratio $(\mathrm{OR})$ was $2.08(95 \%$ confidence interval $(\mathrm{CI})=0.17$ 24.6) in NTD mothers vs control mothers, with a P value of 0.5 . Statistical analysis showed no significant difference in genotype frequency in NTD cases $v s$ control children, with an OR $=$ $0.47(95 \% \mathrm{CI}=0.041-5.65)$.

\section{Analysis of DNA sequencing}

The DNA sequencing analysis data showed that the first 45-nucleotide insertion was identical to that of 42 nucleotides at the site of $852 \mathrm{nt}$. The remaining sequence containing 23 nucleotides is identical to the wild-type sequence of the first 21 nucleotides (831-852) from the $5^{\prime}$ end of exon 8 in the normal allele. At the origin of the insertion sequence, five nucleotide bases were replaced by tetra-guanine bases (TCCAT $\rightarrow$ GGGG), and interestingly, the replacement of these bases creates a new recognition site as mentioned above for the restriction enzyme HaeIII and as shown in Figure 2B (by underline in the box).

\section{DISCUSSION}

The etiopathological mechanism of NTDs is highly complex due to the involvement of genetic and epigenetic factors, which lead to defective folic acid metabolism and the associated enzymes fail to convert homocysteine to cysteine. The present study shows that the CBS gene mutation may increase the risk factor 2 -fold in view of $\mathrm{OR}=2.08(95 \% \mathrm{CI}=0.17-24.6)$ and $\mathrm{P}=0.5$ in case mothers, suggesting that the failure of the conversion of homocysteine to cystathionine and cysteine, resulting in homocysteine accumulation, may be one of the causes of NTDs in the fetus.

Presently, there are more than one hundred C $\beta S$ mutations known to be responsible for severe phenotypic changes in patients (Kraus et al., 1999). However, the present study selected the same site of mutation, which affects the C $\beta S$ enzyme activity to identify and to further confirm this mutation through sequencing analysis in cases of NTD (LMMC) and their controls. Earlier studies have also been reported in patients with homocysteinemia and coronary artery disease with insertion of $68 \mathrm{bp}$ in the CBS gene, with deletion of two bases and substitution of two single bases. The present study shows similar findings with deletion of two bases, except that three bases are substituted, which is quite different from the previous reports (Sebastio et al., 1995; Tsai et al., 1996b). The second important finding of the present study is the variation in the position of the insertion of $68 \mathrm{bp}$ at $852 \mathrm{nt}$ instead of $844 \mathrm{nt}$, when compared with the findings of Tsai et al (1996b). To the best of our knowledge, we report here for the first time a novel mutation in this region in NTD patients, confirmed by DNA sequencing data analysis. The variation in the frequency between NTD cases and controls is perhaps due to polymorphic variants, where no single genetic factor is likely to be responsible for NTDs. However, the prevalence of a 68-bp insertion is more common in different populations associated with different clinical lesions (Kluijtmans et al., 1997). Based on our observations with respective cases and controls, we conclude that the C $\beta S$ gene mutation is likely responsible for abnormal differentiation of nervous tissue during ontogenic development of the fetus, which leads to NTDs, suggesting that a genetic factor (mutation) may alone be an independent risk factor for "birth defects". 


\section{ACKNOWLEDGMENTS}

Research supported by the Department of Biotechnology, Ministry of Science \& Technology, Government of India (grant \#BT/PR/9022/MED/12/331/2007).

\section{REFERENCES}

Botto LD, Moore CA, Khoury MJ and Erickson JD (1999). Neural-tube defects. N. Engl. J. Med. 341: 1509-1519.

Kluijtmans LAJ, Boers GHJ, Trijbels FJM and Van Lith-Zanders HMA (1997). Neural tube defects. Biochem. Mol. Med. 62: 23-25.

Kraus JP, Oliveriusova J, Sokolova J, Kraus E, et al. (1998). The human cystathionine beta-synthase (CBS) gene: complete sequence, alternative splicing, and polymorphisms. Genomics 52: 312-324.

Kraus JP, Janosik M, Kozich V, Mandell R, et al. (1999). Cystathionine $\beta$-synthase mutations in homocystinuria. Hum. Mutat. 13: 362-375.

Miller SA, Dykes DD and Polesky HF (1988). A simple salting out procedure for extracting DNA from human nucleated cells. Nucleic Acids Res. 16: 1215.

Moore CA, Li S, Li Z, Hong SX, et al. (1997). Elevated rates of severe neural tube defects in a high-prevalence area in northern China. Am. J. Med. Genet. 73: 113-118.

Mosley BS, Cleves MA, Siega-Riz AM, Shaw GM, et al. (2009). Neural tube defects and maternal folate intake among pregnancies conceived after folic acid fortification in the United States. Am. J. Epidemiol. 169: 9-17.

Mudd SH, Levy HL and Kraus JP (2001). From Disorders of Transsulfuration. In: The Metabolic and Molecular Bases of Inherited Disease. 8th edn. (Scriver CR, Beaudet AL, Sly WS, Valle D, et al., eds.). McGraw-Hill, New York, 2007-2056.

Munke M, Kraus JP, Ohura T and Francke U (1988). The gene for cystathionine $\beta$-synthase (CBS) maps to the subtelomeric region on human chromosome 21q and to proximal mouse chromosome 17. Am. J. Hum. Genet. 42: 550-559.

Sebastio G, Sperandeo MP, Panico M, de FR, et al. (1995). The molecular basis of homocystinuria due to cystathionine beta-synthase deficiency in Italian families, and report of four novel mutations. Am. J. Hum. Genet. 56: 1324-1333.

Sperandeo MP, de Francis R, Andria G and Sebastio G (1996). A 68-bp insertion found in a homocystinuric patient is a common variant and is skipped by alternative splicing of the cystathionine $\beta$-synthase mRNA. Am. J. Hum. Genet. 59: 1391-1393.

Thomas JA, Markovac J and Ganong WF (1994). Anencephaly and other neural tube defects. Front Neuroendocrinol. 15: 197-201.

Tsai MY, Garg U, Key NS, Hanson NQ, et al. (1996a). Molecular and biochemical approaches in the identification of heterozygotes for homocystinuria. Atherosclerosis 122: 69-77.

Tsai MY, Bignell M, Schwichtenberg K and Hanson NQ (1996b). High prevalence of a mutation in the cystathionine betasynthase gene. Am. J. Hum. Genet. 59: 1262-1267. 